\title{
Impacts of Climate Change on Net Primary Productivity in Arid and Semiarid Regions of China
}

\author{
WANG Hao, LIU Guohua, LI Zongshan, YE Xin, WANG Meng, GONG Li \\ (State Key Laboratory of Urban and Regional Ecology, Research Center for Eco-Environmental Science, Chinese Academy of Sciences, \\ Beijing 100085, China)
}

\begin{abstract}
In recent years, with the constant change in the global climate, the effect of climate factors on net primary productivity (NPP) has become a hot research topic. However, two opposing views have been presented in this research area: global NPP increases with global warming, and global NPP decreases with global warming. The main reasons for these two opposite results are the tremendous differences among seasonal and annual climate variables, and the growth of plants in accordance with these climate variables. Therefore, it will fail to fully clarify the relation between vegetation growth and climate changes by research that relies solely on annual data. With seasonal climate variables, we may clarify the relation between vegetation growth and climate changes more accurately. Our research examined the arid and semiarid areas in China (ASAC), which account for one quarter of the total area of China. The ecological environment of these areas is fragile and easily affected by human activities. We analyzed the influence of climate changes, especially the changes in seasonal climate variables, on NPP, with Climatic Research Unit (CRU) climatic data and Moderate Resolution Imaging Spectroradiometer (MODIS) satellite remote data, for the years 2000-2010. The results indicate that: for annual climatic data, the percentage of the ASAC in which NPP is positively correlated with temperature is $66.11 \%$, and $91.47 \%$ of the ASAC demonstrates a positive correlation between NPP and precipitation. Precipitation is more positively correlated with NPP than temperature in the ASAC. For seasonal climatic data, the correlation between NPP and spring temperature shows significant regional differences. Positive correlation areas are concentrated in the eastern portion of the ASAC, while the western section of the ASAC generally shows a negative correlation. However, in summer, most areas in the ASAC show a negative correlation between NPP and temperature. In autumn, precipitation is less important in the west, as opposed to the east, in which it is critically important. Temperatures in winter are a limiting factor for NPP throughout the region. The findings of this research not only underline the importance of seasonal climate variables for vegetation growth, but also suggest that the effects of seasonal climate variables on NPP should be explored further in related research in the future. Keywords: climate change; net primary productivity (NPP); annual/seasonal variability; trend analysis; arid/semiarid regions of China (ASAC)
\end{abstract}

Citation: Wang Hao, Liu Guohua, Li Zongshan, Ye Xin, Wang Meng, Gong Li, 2016. Impacts of climate change on net primary productivity in arid and semiarid regions of China. Chinese Geographical Science, 26(1): 35-47. doi: 10.1007/s11769-015-0762-1

\section{Introduction}

Terrestrial net primary productivity (NPP) is the primary factor involved in identifying ecosystem carbon sources and carbon sequestration, and is one of the main sources of human food resources, wood products and fuel
(Knapp and Smith, 2001; Zhou et al., 2002). NPP not only reflects the natural vegetation production capacity and the quality of terrestrial ecosystems, but also plays an important role in gauging terrestrial ecosystem sustainable development ability (Myneni et al., 2001). Many studies have shown that global warming scenarios

Received data: 2014-08-26; accepted data: 2014-11-21

Foundation item: Under the auspices of the Strategic Priority Research Program-Climate Change: Carbon Budget and Relevant Issues of Chinese Academy of Sciences (No. XDA05060104) Corresponding author: LIU Guohua. E-mail: ghliu@rcees.ac.cn

(C) Science Press, Northeast Institute of Geography and Agroecology, CAS and Springer-Verlag Berlin Heidelberg 2016 
are becoming increasingly observable (Houghton et al., 2001). The Intergovernmental Panel on Climate Change (IPCC) report indicates that the global average temperature has risen by $0.74^{\circ} \mathrm{C}$ over the past 100 years (1906-2005), with a warming rate of $0.13^{\circ} \mathrm{C} /$ decade in the most recent 50 years (IPCC, 2007). An emerging body of literature suggests that climate change has a pronounced impact on global terrestrial NPP (Houghton et al., 1999; Houghton, 2002; Nemani et al., 2002). A precise understanding of the driving mechanisms of climate change on NPP variability has important theoretical and practical implications for evaluating the environmental quality of terrestrial ecosystems, regulating the ecological process, and estimating the terrestrial carbon sink (Friend et al., 2014).

A number of studies have been conducted about the impact of climate change on NPP (Melillo et al., 1993; Keeling et al., 1996; Cao and Woodward, 1998; Tian et al., 1999; Zhou et al., 2001; Hicke et al., 2002). Nemani et al. (2003) pointed out that climatic changes have eased multiple climatic constraints on plant growth, and have increased NPP over large regions of Earth. However, based on Moderate Resolution Imaging Spectroradiometer (MODIS) satellite remote data, Zhao and Running (2010) reported that NPP declined over the past decade, with large-scale droughts being responsible for the decline. The main reasons for these conflicting results are the large differences among seasonal and annual climate variables, and the growth of plants in accordance with different climate variables. Most previous studies have simply focused on inter-annual changes in annual NPP at the global or regional scale (Zhou and Zhang, 1996; Zheng et al., 1997; Piao et al., 2001). Del et al. (2008) found a 13\% increase in total global NPP for potential vegetation from 1901 to 2000 based on changing precipitation and temperature patterns. Knapp and Smith (2001) found a significantly positive correlation between NPP and precipitation in their researches. A number of studies have indicated that China's terrestrial NPP is changing due to climate change (Gao Zhiqiang et al., 2004; Gao et al., 2009; Wang et al., 2009; Chen et al., 2011). In order to better understand the mechanisms of NPP and illuminate the responses of vegetation NPP to global change, more analyses have now been conducted on interannual variations in the seasonal vegetation activity (Hicke et al., 2002; Piao et al., 2003). Piao et al. (2008) found that in the northern hemisphere, warming increased photosynthesis more than respiration in the spring; in contrast, in autumn, the increase in respiration was greater than the increase in photosynthesis. Wang et al. (2011) found that lower spring and summer temperatures may contribute to the growth of summer plants in North America. In eastern China, Li Z S et al. (2011) pointed out that winter climate conditions play an important role in modulating the forest NPP of the eastern China, and that spring temperature had a positive effect on NPP, while forest NPP was negatively affected by summer and autumn temperatures. In general, studies on seasonal responses of terrestrial NPP to climate changes contribute to understanding the feedback between climate systems and terrestrial ecosystems and mechanisms of changes in NPP.

The arid and semiarid areas in China (ASAC) are the most arid regions in the world and include nearly all major sand/desert regions of China (Shi et al., 2007). In this region, the scarcity of water, the fragile ecological environment, and the influences of human activities make the ASAC extremely sensitive to abnormal changes in water and heat, such as global warming (Narisma et al., 2007; Chen et al., 2010; Dai, 2011). Based on temperature data for the years 1961-1997, Li and Qian (2005) indicated that temperatures in the ASAC kept increasing, especially winter temperatures. Shi et al. (2003) research indicates that the climate of the ASAC is becoming warmer and wetter. Ren and Yang (2006) used climatic data during 1961-2000 to analyze climatic changes in Northwest China and found that the temperature of the ASAC was increasing at a rate of $0.22^{\circ} \mathrm{C} /$ decade. Such significant climate changes will certainly give rise to corresponding changes in NPP in this area. However, most researches in this region have only focused on the interannual changes in annual NPP (Chen et al., 2012; Cheng et al., 2012; Peng et al., 2012), and little attention has been paid to the influence of seasonal climatic changes on vegetation growth in this area.

Therefore, in this study, we used the Climatic Research Unit (CRU) climatic data and MODIS satellite remote data for the ASAC to examine changes in the trend of climatic and NPP variables for the 2000-2010 period. More specifically, by analyzing the correlation coefficients between seasonal climatic data and NPP data, we aimed to: 1) quantify changes in climate vari- 
ables (temperature and precipitation) in the ASAC over the past decade; 2) quantify changes in NPP in the ASAC, and determine the spatio-temporal patterns of NPP during 2000-2010; and 3) clarify the influence of climatic change on NPP in the ASAC.

\section{Materials and Methods}

\subsection{Study area}

The arid and semiarid areas in China cover an area of approximately $2430000 \mathrm{~km}^{2}$ between $36.73-49.95^{\circ} \mathrm{N}$ and $73.43-123.92^{\circ} \mathrm{E}$ (Fig. 1), which amounts to nearly one quarter of the total area of China (Li Fei et al., 2011). The terrain in the western region of the ASAC is rugged and elevated, with Kunlun, Altun and Qilian mountains separating it from the Tibetan Plateau (Department of Geography, 1984). The ASAC mainly includes the temperate grassland of Inner Mongolia, the northwestern temperate region and the warm temperate desert region. Bounded by Helan Mountain, precipitation in the eastern and the western ASAC differs markedly. The western ASAC includes the Alxa Desert, temperate desert in the Junggar Basin, mountainous coniferous forests in the Altay Mountains, mountainous coniferous forests in the Tianshan Mountains, and warm temperate desert in the Tarim Basin. The annual precipitation in this area is generally below $200 \mathrm{~mm}$. The area, a typical arid region, is characterized by desert, wind erosion landforms, sparse and undersized vegetation, dust storms, and drought. The eastern ASAC is composed of steppes in the Xiliao River Basin, steppes and desert grassland on the Inner Mongolian Plateau, and steppes and desert grassland on the Ordos Plateau. The annual precipitation in this area reaches between 200-400 mm. In this semi arid and dry sub-humid area, grassland and farmland crisscross. The vegetation in this area is badly damaged, and the natural conditions of this area are relatively poor in comparison with other areas of China (Wang et al., 1999; Shi et al., 2007).

\subsection{Dataset}

\subsubsection{Climatic data}

In this study, we used the Climatic Research Unit (CRU) climatic data offered by the University of East Anglia (http://badc.nerc.ac.uk/browse/badc/cru/data/cru_ts/cru ts $3.21 / \mathrm{data} /$ ). The CRU is a monthly dataset with complete coverage of land surface climatic variables. The time range of CRU is from 1901 to the present, and the spatial resolution is $0.5^{\circ} \times 0.5^{\circ}$ (Jones and Moberg, 2003). The CRU climatic data presents 9 variables, including average temperature, maximum temperature, minimum temperature, precipitation, cloud cover, diurnal range, vapor pressure, frost days and dew days. Average temperature and precipitation monthly data from 2000-2010 were used in this study.

In comparison with domestic observations, the CRU has certain merits with regard to climate change over the 20th century. No proxies' data are included in the construction of the CRU dataset, which can give rise to noise and uncertainty. The CRU dataset in China not only contains the observational data published by China's National Climate Center, but also data from individual observation stations. Therefore, the CRU dataset has become a relatively complete climatic dataset of

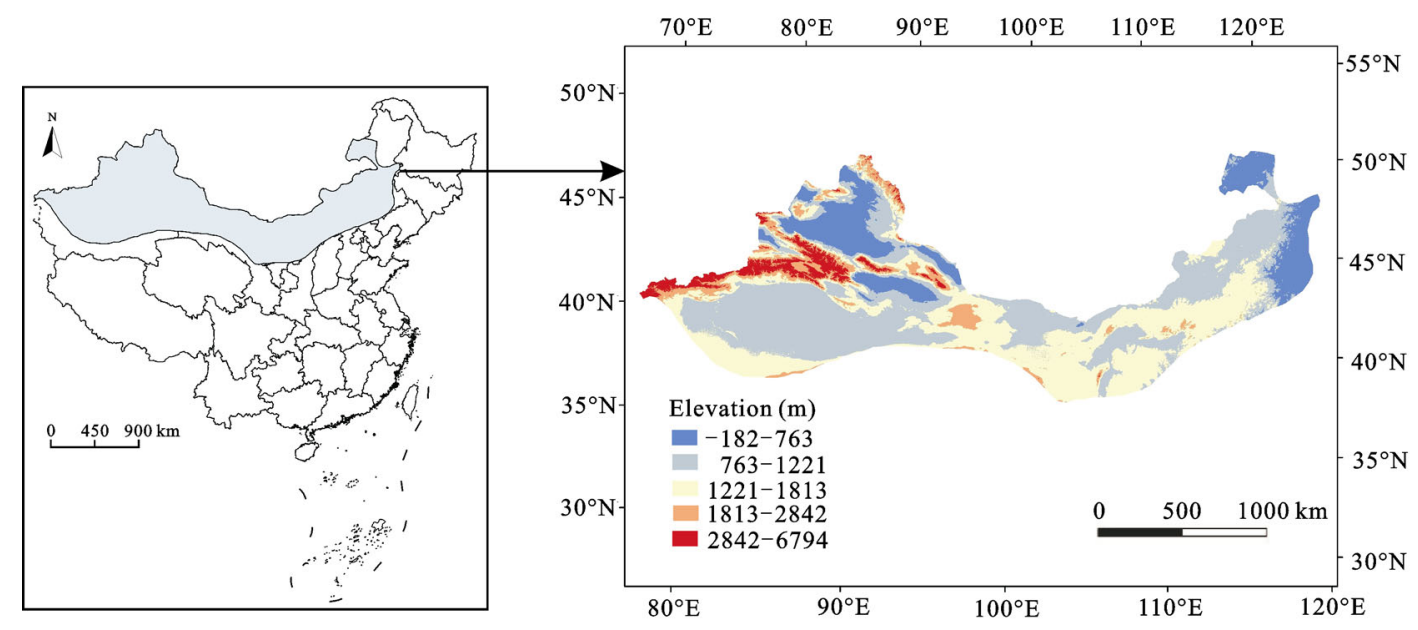

Fig. 1 Topographical view of arid and semiarid areas in Northwest China, based on DEM map, $90 \mathrm{~m}$ resolution, data are from http:// datamirror.csdb.cn/ 
climate change in China over the last 100 years (Mitchell and Jones, 2005). Wen et al. (2006) compared the climatic dataset of CRU with China's National Climate Center. The results highlight the fact that CRU data exhibits appropriate inter-decadal variation of temperature and precipitation, as shown in China's records.

\subsubsection{Remote data}

The NPP data in the ASAC for 2000 to 2010 were collected from NASA (National Aeronautics and Space Administration), MODIS, satellite data (https://earthdata.nasa.gov/). Its spatial resolution is $1 \mathrm{~km}$. The data number is MOD17A3, and the temporal resolution is one year. At present, NPP data are already widely used and have been validated in vegetation growing condition assessments, biomass estimations and environment monitoring (Zhao et al., 2005).

\subsection{Spatial distribution and trends detection}

In this study, temperature and precipitation were adopted as two elements of climatic data. Annual data and seasonal data were calculated from monthly data. March to May was considered as spring, June to August was considered as summer, September to November was considered as autumn, and December to February was considered as winter. Temporal and spatial distributions of annual and seasonal data were calculated using the software ArcGIS (version 9.3) to reveal the relationship between climatic elements and NPP.

The least square method based on a linear regression was used to estimate the climatic elements and NPP change rate (Zhang et al., 2013).

$b=\frac{\sum_{i=1}^{n} x_{i} y_{i}-\frac{1}{n}\left(\sum_{i=1}^{n} x_{i}\right)\left(\sum_{i=1}^{n} y_{i}\right)}{\sum_{i=1}^{n} x_{i}^{2}-\frac{1}{n}\left(\sum_{i=1}^{n} x_{i}\right)^{2}}$

where $b$ is the change rate; $x_{i}$ is the order of year from 1 to $n$; and $n$ is the number of years; $y_{i}$ refers to the climatic variables or NPP variables when time is $x_{i}$.

The formula for the correlation coefficient was used to estimate the correlation between annual NPP and annual or seasonal climatic variables.

$$
r=\frac{n \sum_{i=1}^{n} x_{i} y_{i}-\sum_{i=1}^{n} x_{i} \cdot \sum_{i=1}^{n} y_{i}}{\sqrt{n \sum_{i=1}^{n} x_{i}^{2}-\left(\sum_{i=1}^{n} x_{i}\right)^{2}} \cdot \sqrt{n \sum_{i=1}^{n} y_{i}^{2}-\left(\sum_{i=1}^{n} y_{i}\right)^{2}}}
$$

where $r$ is the Pearson correlation coefficient; $i$ is the order of year from 1 to $n$; and $n$ is the number of years; $x_{i}$ encompasses the NPP variables when time is $i$; and $y_{i}$ refers to the climatic variables when time is $i$ (Zhao and Running, 2010).

\section{Results}

\subsection{Temporal climate trends}

With a vast area and complex topography, the ASAC displays a wide variety of microclimates. Table 1 presents the essential average annual climate variables of the ASAC for the years 2000-2010. The mean annual temperature in this area is $7.16^{\circ} \mathrm{C}$. The mean seasonal temperatures are $9.28^{\circ} \mathrm{C}$ for spring, $22.07^{\circ} \mathrm{C}$ for summer, $7.39^{\circ} \mathrm{C}$ for autumn, and $-9.54^{\circ} \mathrm{C}$ for winter (Table 1 ). Analysis reveals that the temperature in this area increased by $0.048^{\circ} \mathrm{C} / \mathrm{yr}$ from 2000 to 2010 (Table 1). The mean temperatures for the four seasons have their own trend that differs from that of the annual mean temperature. In spring and summer, mean temperature shows a downward trend, but in autumn, mean temperature increases. Winter mean temperature shows a non-significant trend (Table 1). Autumn mean temperature has the greatest rate of change, and the sum of the rate of change for autumn and winter is greater than for spring and summer; thus, although spring and summer have grown colder, the annual mean temperature still presented an increasing trend.

The mean precipitation in the ASAC for the years 2000-2010 is $172.39 \mathrm{~mm}$, with great variations among the seasons. The mean precipitation is $35.47 \mathrm{~mm}$ in spring, $94.05 \mathrm{~mm}$ in summer, $34.44 \mathrm{~mm}$ in autumn, and $10.42 \mathrm{~mm}$ in winter (Table 1). The precipitation in this area was also found to be increasing, with a rate of change of $0.771 \mathrm{~mm} / \mathrm{yr}$ (Table 1). Across the different seasons, the precipitation change trend differs and becomes even more complicated. In spring and autumn, precipitation shows an upward trend, but in summer, it decreases. The winter precipitation trend remains unclear (Table 1). Summer precipitation has the greatest change rate, but the sum of the changing rates of the other seasons is greater than that of summer; thus, the annual mean precipitation still presented an increasing trend.

\subsection{Spatial climate trends}

Climatic changes in the ASAC are not only reflected on 
Table 1 Temperature, precipitation and NPP in ASAC during $2000-2010$

\begin{tabular}{lrrrc}
\hline \multicolumn{1}{c}{ Variable } & Mean & \multicolumn{1}{c}{ SD } & Rate & $R^{2}$ \\
\hline TMP $\left({ }^{\circ} \mathrm{C}\right)$ & 7.16 & 0.5 & 0.048 & 0.102 \\
TMP-SP $\left({ }^{\circ} \mathrm{C}\right)$ & 9.28 & 0.97 & -0.038 & 0.016 \\
TMP-SU $\left({ }^{\circ} \mathrm{C}\right)$ & 22.07 & 0.41 & -0.033 & 0.073 \\
TMP-AU $\left({ }^{\circ} \mathrm{C}\right)$ & 7.39 & 0.72 & 0.072 & 0.112 \\
TMP-WI $\left({ }^{\circ} \mathrm{C}\right)$ & -9.54 & 1.29 & 0.013 & 0.001 \\
PRE $(\mathrm{mm})$ & 172.39 & 24.25 & 0.771 & 0.011 \\
PRE-SP $(\mathrm{mm})$ & 35.47 & 11.66 & 1.037 & 0.087 \\
PRE-SU $(\mathrm{mm})$ & 94.05 & 15.98 & -1.323 & 0.075 \\
PRE-AU $(\mathrm{mm})$ & 34.44 & 8.84 & 1.05 & 0.155 \\
PRE-WI $(\mathrm{mm})$ & 10.42 & 2.39 & 0.006 & 0.001 \\
NPP $\left(\mathrm{g} \mathrm{C} / \mathrm{m}^{2}\right)$ & 159.31 & 11.14 & 0.437 & 0.017 \\
\hline
\end{tabular}

Notes: Mean is the average value of the variables from 2000 to 2010. SD is the standard deviation of mean. $R^{2}$ and rate represent the correlation coefficient and the slope of linear regression, respectively. TMP is mean temperature, PRE is mean precipitation, and NPP is mean NPP. TMP-SP is spring mean temperature, TMP-SU is summer mean temperature, TMP-AU is autumn mean temperature and TMP-WI is winter mean temperature. PRE-SP is spring precipitation, PRE-SU is summer precipitation, PRE-AU is autumn precipitation and PRE-WI is winter precipitation

the time scale, but also embodied in the spatial scale. Figure 2a shows the spatial distribution of mean annual temperature. Thus, for example, the warm centre of the ASAC is located in the Taklimakan Desert in Xinjiang Province, and the cold centre is located in the Da Hinggan and Tianshan Mountains. Annual temperature rates of change in this area range from $-0.21^{\circ} \mathrm{C} / \mathrm{yr}$ to $0.12^{\circ} \mathrm{C} / \mathrm{yr}$ (Fig. 2 b). $87.16 \%$ of the area in the ASAC shows an increasing trend for temperature; only $12.84 \%$ area displays a decreasing trend. Significant increasing areas cover $16.7 \%$ of the entire region, an amount considerably larger than areas with a significant decrease, which amount to only $2.84 \%$ for the entire area (Table 2). The temperature in the Taklimakan Desert and Otindag Sandy Land are increasing markedly, but to the north of Helan Mountain, the temperature is clearly decreasing (Fig. 2b). Figure 3 shows the spatial patterns of temperature with the linear trends for the four seasons in the ASAC from 2000 to 2010 . The results indicate that in autumn, $92.65 \%$ of the area in the ASAC, the largest amount of all the seasons, experiences an increasing trend for temperature. With $68.82 \%$, winter has the second largest percentage. In summer, $60.97 \%$ of the area in the ASAC displays an increasing trend for temperature, while spring has the lowest percentage at $29.91 \%$ (Table 2). The area in which temperature is increasing
Table 2 Spatial changes of temperature, precipitation and NPP in ASAC during 2000-2010

\begin{tabular}{lcccc}
\hline \multicolumn{1}{c}{ Variable } & $\begin{array}{c}\text { Increasing } \\
(\%)\end{array}$ & $\begin{array}{c}\text { Decreasing } \\
(\%)\end{array}$ & $\begin{array}{c}\text { Significant } \\
\text { increasing }(\%)\end{array}$ & $\begin{array}{c}\text { Significant } \\
\text { decreasing }(\%)\end{array}$ \\
\hline TMP $\left({ }^{\circ} \mathrm{C}\right)$ & 87.16 & 12.84 & 16.70 & 2.84 \\
TMP-SP $\left({ }^{\circ} \mathrm{C}\right)$ & 29.91 & 70.09 & 0 & 0.48 \\
TMP-SU $\left({ }^{\circ} \mathrm{C}\right)$ & 60.97 & 39.03 & 0 & 1.62 \\
TMP-AU $\left({ }^{\circ} \mathrm{C}\right)$ & 92.65 & 7.35 & 2.02 & 0.95 \\
TMP-WI $\left({ }^{\circ} \mathrm{C}\right)$ & 68.82 & 31.18 & 0 & 1.73 \\
PRE $(\mathrm{mm})$ & 67.03 & 32.97 & 1.54 & 0.79 \\
PRE-SP $(\mathrm{mm})$ & 80.23 & 19.77 & 3.95 & 0 \\
PRE-SU (mm) & 26.98 & 73.02 & 0 & 8.76 \\
PRE-AU $(\mathrm{mm})$ & 80.77 & 19.23 & 9.03 & 0 \\
PRE-WI $(\mathrm{mm})$ & 49.62 & 50.38 & 8.37 & 3.62 \\
NPP $\left(\mathrm{g} \mathrm{C} / \mathrm{m}^{2}\right)$ & 59.04 & 40.96 & 10.04 & 4.38 \\
\hline
\end{tabular}

Notes: significant increasing/decreasing is significant changed areas (percentages) shown significant $(P<0.05)$ increasing/decreasing linear trend. TMP is mean temperature, PRE is mean precipitation, and NPP is mean NPP. TMP-SP is spring mean temperature, TMP-SU is summer mean temperature, TMP-AU is autumn mean temperature and TMP-WI is winter mean temperature. PRE-SP is spring precipitation, PRE-SU is summer precipitation, PRE-AU is autumn precipitation and PRE-WI is winter precipitation

significantly in spring is in the Taklimakan Desert, which experiences a similar situation in the winter. But in summer, temperatures in Otindag Sandy Land clearly increase. Autumn is unique, as temperatures clearly rise north of the Tianshan Mountains. Areas with a significant temperature decrease in the ASAC are located east of Da Hinggan Mountains in spring and summer, north of Helan Mountain in autumn and in the Altay Mountains in winter (Fig. 3).

The spatial distribution of mean annual precipitation also has regional characteristics. From the perspective of the spatial distribution of precipitation, the ASAC can clearly be divided into two areas roughly delineated by Helan Mountain (approximately $38^{\circ} \mathrm{N}$ and $108^{\circ} \mathrm{E}$ ). East of the Helan Mountain is the semiarid region of China, where the climate is relatively humid. In contrast, west of the Helan Mountain is the arid region of China, which is characterized by a drought climate (Fig. 2a). Annual precipitation rates of change in the ASAC range from $-10.16 \mathrm{~mm} / \mathrm{yr}$ to $10.26 \mathrm{~mm} / \mathrm{yr}$ (Fig. $2 b$ ). The total of $67.03 \%$ of the area in the ASAC represents an increasing trend for precipitation; $32.97 \%$ of the area represents a decreasing trend. The $1.54 \%$ of the entire area shows a significant increase, considerably larger than the area in which a significant decrease is found, which accounts for only $0.54 \%$ of the entire area (Table 
2). Precipitation in the south of Da Hinggan Mountains and Otindag Sandy Land is increasing considerably, but the east of Da Hinggan Mountains and the south of the Altay Mountains, the temperature is clearly decreasing (Fig. 2b). Figure 3 shows the spatial patterns of the linear trends of precipitation for all four seasons in the ASAC from 2000 to 2010 . The results indicate that in autumn, $80.77 \%$ of the area in the ASAC, the largest percentage for all seasons, displays an increasing trend for precipitation. Spring ranks second at $80.23 \%$. In winter, the area amounts to $49.62 \%$. With $26.98 \%$, summer is in last place (Table 2). The area in which precipitation is increasing significantly in spring is distributed east of Da Hinggan Mountains and the Tianshan Mountains. In summer, precipitation in $\mathrm{Mu}$ Us Desert increases markedly. Autumn is unique, as precipitation clearly increases north of the Kunlun Mountains and Otindag Sandy. In Hulun Buir Sandy and the Altay Mountains, precipitation clearly increases in winter. Areas with significant precipitation decrease in the ASAC are located the south of the Altay Mountains in spring, the east of Da Hinggan Mountains in summer and $\mathrm{Mu}$ Us Desert in autumn, and in the Tianshan Mountains in winter (Fig. 3).

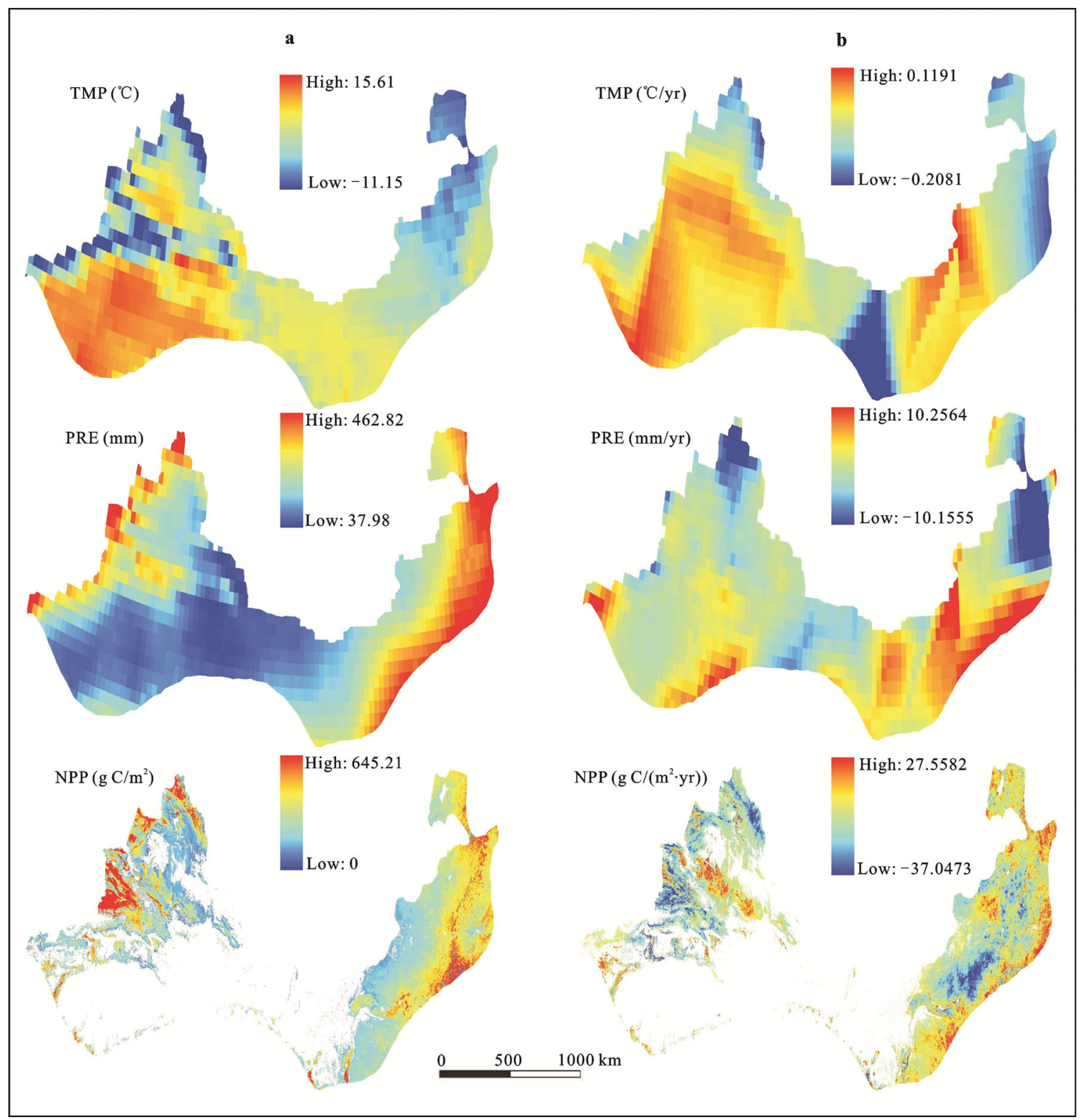

Fig. 2 Spatial patterns of mean temperature (TMP), mean precipitation (PRE) and mean NPP (NPP) over 11 years, from 2000 to 2010 (a). Spatial patterns of annual mean temperature (TMP), annual mean precipitation (PRE) and annual mean NPP, linear trend from 2000 to 2010 (b). The blank area in figure represents a non-vegetation area, such as a desert, urban areas, ice, and the like 


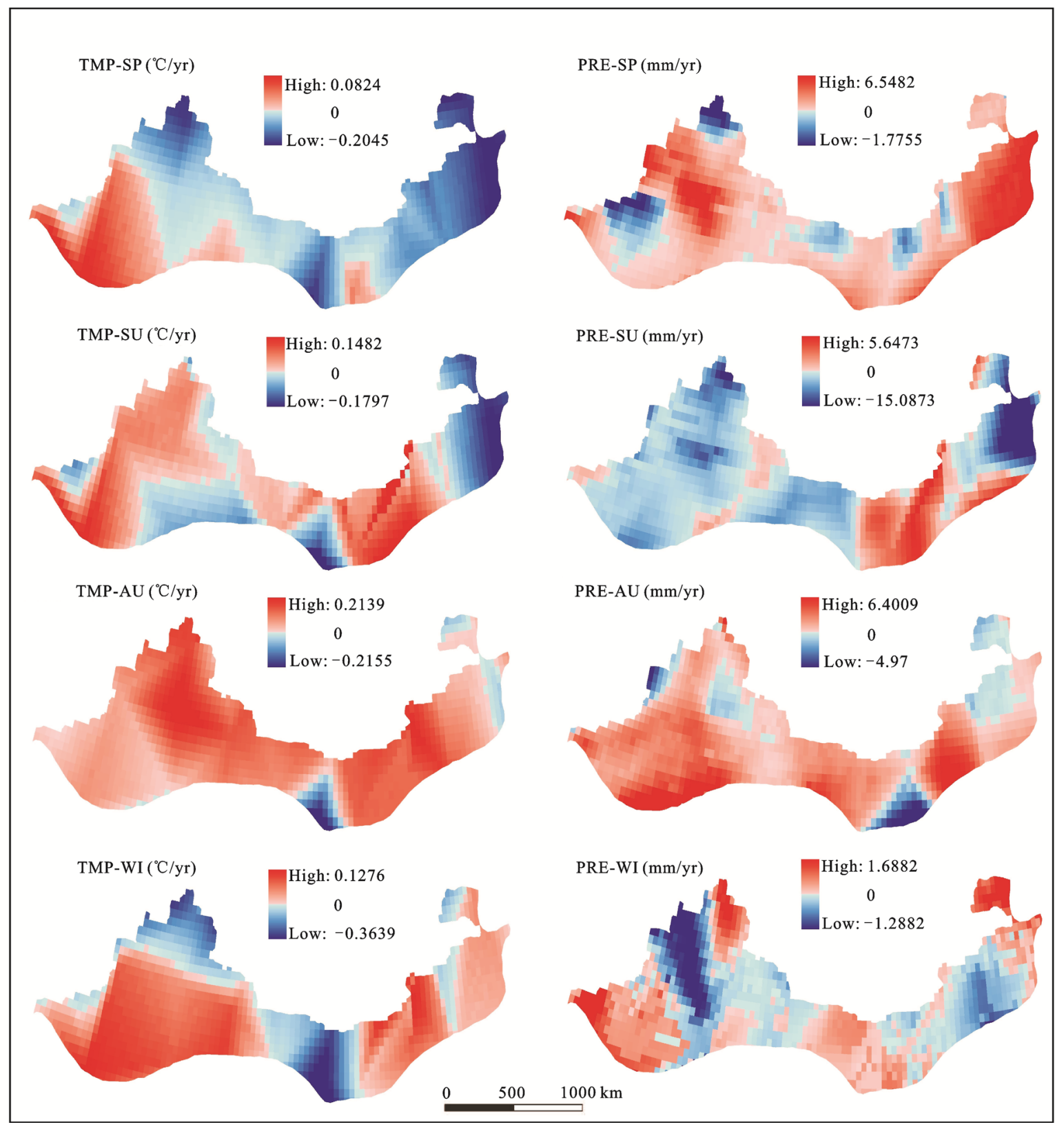

Fig. 3 Spatial patterns of spring mean temperature (TMP-SP), summer mean temperature (TMP-SU), autumn mean temperature (TMP-AU), winter mean temperature (TMP-WI), spring precipitation (PRE-SP), summer precipitation (PRE-SU), autumn precipitation (PRE-AU) and winter precipitation (PRE-WI) linear trends from 2000 to 2010

Overall, the climate in the ASAC is becoming warmer and wetter.

\subsection{Temporal and spatial NPP trends}

The average annual NPP in the ASAC is $159.31 \mathrm{~g} \mathrm{C} / \mathrm{m}^{2}$ for the period from 2000 to 2010 (Table 1). According to our analysis, NPP in the ASAC has shown an increasing trend over the last decade with a rate of change of $0.437 \mathrm{~g}$ $\mathrm{C} /\left(\mathrm{m}^{2} \cdot \mathrm{yr}\right)$. The maximum and minimum annual mean NPP was $179.11 \mathrm{~g} \mathrm{C}^{2} \mathrm{~m}^{2}$ in 2003 and $141.95 \mathrm{~g} \mathrm{C} / \mathrm{m}^{2}$ in
2001, respectively (Table 1).

Annual NPP rates of change in this area ranged between $-37.05 \mathrm{~g} \mathrm{C} /\left(\mathrm{m}^{2} \cdot \mathrm{yr}\right.$ ) and $27.56 \mathrm{~g} \mathrm{C} /\left(\mathrm{m}^{2} \cdot \mathrm{yr}\right.$ ) (Fig. 2B). $59.04 \%$ of the area in the ASAC demonstrates an increasing trend for NPP, while $40.96 \%$ of the area displays a decreasing trend. Significant areas of increase amount to $10.04 \%$ for the whole area, which is considerably larger than significant areas of decrease, which is only $4.38 \%$ for the entire area (Table 2). The NPP in the east of the Da Hinggan Mountains and Tianshan Moun- 
tains are increasing markedly, but in the south of the Tianshan Mountains, the east of Mu Us Desert and the south of Altay Mountains, the NPP is clearly decreasing (Fig. 2B).

Based on the analysis, the NPP in the ASAC has increased in recent years; vegetation conditions in this area have improved substantially.

\subsection{Correlations between NPP and climate}

Correlation analysis shows that most of the area in the ASAC presents a positive correlation between NPP and annual mean temperature, with a percentage of $66.11 \%$ (Table 3 ). High positive relativity areas are concentrated in the Da Hinggan Mountains and Tianshan Mountains (Fig. 4). However, the results demonstrate a large difference with regard to the correlation between NPP and seasonal temperature. Figure 4 shows the spatial distribution of correlations between NPP and seasonal temperature, which has distinctive regional characteristics. The area in which NPP is positively correlated with spring mean temperature accounts for $55.01 \%$ of the total area (Table 3 ). These areas are mostly in the eastern ASAC (Otindag Sandy Land and Mu Us Desert), while the western ASAC generally showed a negative correlation. In summer, the area shows a positive correlation, amounting to only $8.52 \%$ (Table 3 ), with only a small area in the western ASAC in the Tianshan and Altay Mountains. In contrast with spring, the eastern ASAC generally showed a negative correlation. Autumn differs as well with a positive correlation area ratio of $54.07 \%$ (Table 3); the positive correlation area in the eastern and western ASAC is distributed in Da Hinggan Mountains, Altay Mountains and the Tianshan Mountains. With $74.81 \%$, winter observes the highest positive correlation area ratio (Table 3). Moreover, most areas in the eastern ASAC and some areas, such as the Altay Mountains and the Tianshan Mountains in the western ASAC, demonstrate positive correlations (Fig. 4).

The correlation between NPP and annual precipitation is reflected in Fig. 4 as well. According to the results, $91.47 \%$ of the area displays a positive correlation (Table 3). Just as with temperature data, spatial distribution and positive correlation area also changed when seasonal precipitation data are considered. The area percentage for NPP is positively correlated with spring precipitation, with $71.90 \%$ of correlation (Table 3 ); the negative correlation area is concentrated in the eastern ASAC in the Da Hinggan Ling Prefecture. In summer, the positive correlation area percentage is $89.4 \%$ (Table 3 ), with the Tianshan Mountains, a mere fraction of the western ASAC, showing a negative correlation. The positive correlation area percentage is $60.45 \%$ for autumn (Table 3 ), with the regions distributed in Da Hinggan Mountains, Otindag Sandy Land and Mu Us Desert. The lowest positive correlation area percentage $(44.20 \%)$ is that of winter (Table 3). The regions are distributed in the Otindag Sandy Land and Tianshan Mountains (Fig. 4).

The results presented above demonstrate that for seasonal climatic data, the correlation between NPP and temperature and the correlation between NPP and precipitation display a large number of discrepancies from the annual data.

\section{Discussion}

Based on the analysis of CRU climatic data, we found that both annual temperature and annual precipitation in ASAC increased from 2000 to 2010. The rate of change in annual temperature is $0.048^{\circ} \mathrm{C} / \mathrm{yr}$, which is greater than the global rate of change in annual temperature $\left(0.014^{\circ} \mathrm{C} / \mathrm{yr}\right.$; Brohan et al., 2006; IPCC, 2007) and in the rate of change in annual temperature in China $\left(0.026^{\circ} \mathrm{C} / \mathrm{yr}\right.$; Zhai et al., 1999; Liu et al., 2004; Huang et al., 2005). With regard to seasonal dynamics, winter temperatures are increasing, but the trend is not obvious. Yao et al. (2013) pointed out that winter temperatures in arid areas of Northwest China were clearly rising prior to the year 2000, but the change trend flattened out after the year 2000. The rate of change in annual precipitation is $0.77 \mathrm{~mm} / \mathrm{yr}$, which is greater than the rate of change

Table 3 Spatial statistics of correlation analysis between climate and NPP

\begin{tabular}{lcc}
\hline Variables & Positive correlation (\%) & Negative correlation (\%) \\
\hline NPP-TMP & 66.11 & 33.89 \\
NPP-TMP(SP) & 55.01 & 44.99 \\
NPP-TMP(SU) & 8.52 & 91.48 \\
NPP-TMP(AU) & 54.07 & 45.93 \\
NPP-TMP(WI) & 74.81 & 25.19 \\
NPP-PRE & 91.47 & 8.53 \\
NPP-PRE(SP) & 71.90 & 28.10 \\
NPP-PRE(SU) & 89.40 & 10.60 \\
NPP-PRE(AU) & 60.45 & 39.55 \\
NPP-PRE(WI) & 44.20 & 55.80 \\
\hline
\end{tabular}




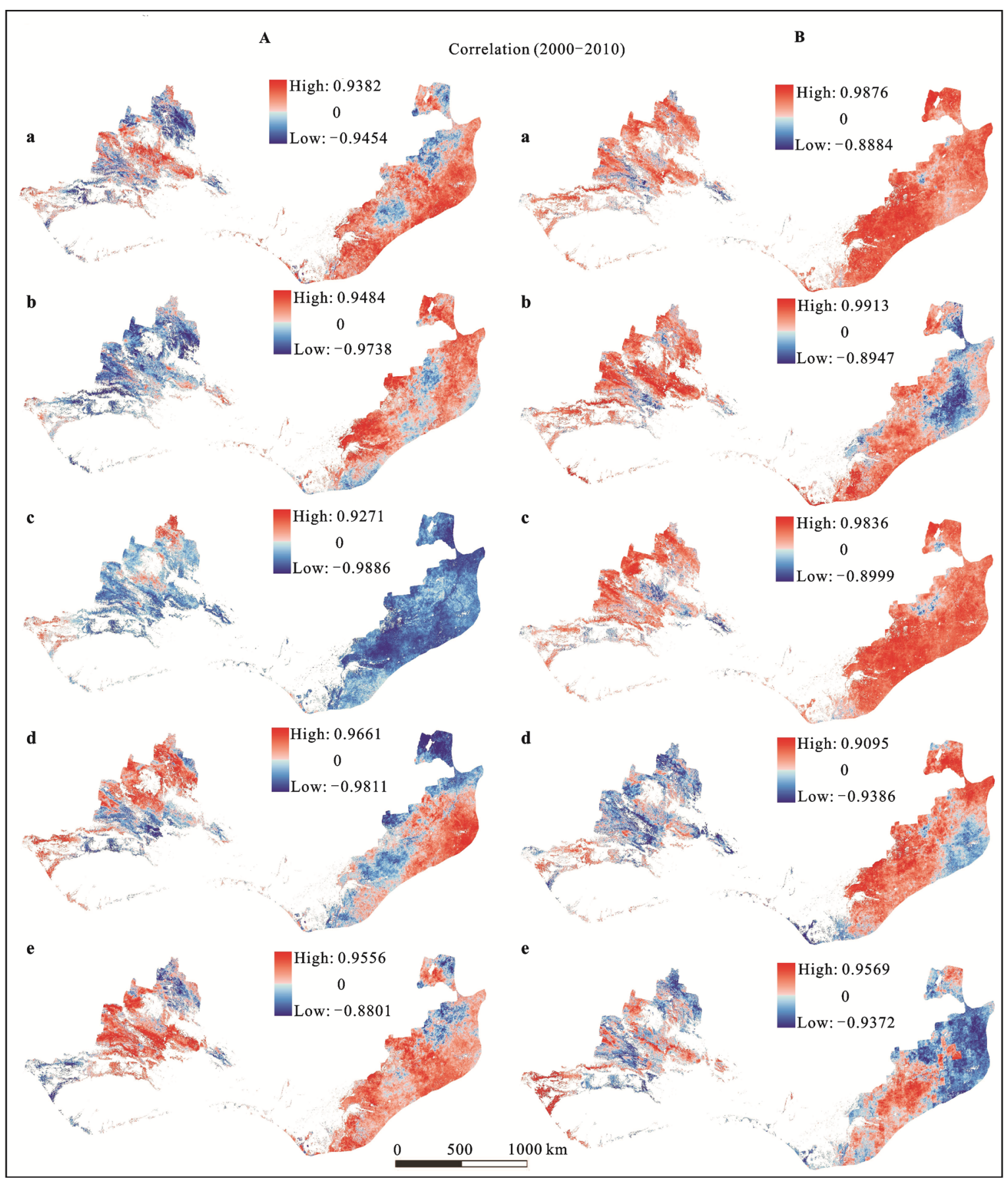

Fig. 4 Spatial patterns of correlations between NPP and temperature (A), annual mean temperature (a), spring mean temperature (b), summer mean temperature (c), autumn mean temperature (d) and winter mean temperature (e). Spatial patterns of correlations between NPP and precipitation (B), annual precipitation (a), spring precipitation (b), summer precipitation (c), autumn precipitation (d) and winter precipitation (e). The blank area in figure NPP represents a non-vegetation area, such as a desert, urban areas, ice, and the like

for annual precipitation in China $(-0.49 \mathrm{~mm} / \mathrm{yr}$; Yu et al., 2011). Overall, the ASAC is growing warmer and wetter, which is similar to that of other studies (Shi et al., 2003; Li and Qian, 2005; Ren and Yang, 2006). Based on research on vegetation coverage change trends in the ASAC, Li et al. (2012) believed in an overall in- crease in both precipitation and temperature, which sequentially prolong the growing season and thus significantly improve the vegetation cover. According to our study, the average annual NPP in the ASAC is $159.31 \mathrm{~g} \mathrm{C} / \mathrm{m}^{2}$, which is lower than the national average (342 $\mathrm{g} \mathrm{C} / \mathrm{m}^{2}$; Tao et al., 2003). However, NPP in the 
ASAC is increasing at a rate of change of $0.437 \mathrm{~g} \mathrm{C} /\left(\mathrm{m}^{2} \cdot \mathrm{yr}\right)$. The spatial distribution indicates that nearly $60 \%$ of areas in the ASAC are witnessing a rising trend, which is closely related to climate change. A change to a warmer and wetter climate turns out to be good for vegetation growth, and therefore promotes the increase of NPP.

We also found precipitation to be far more positively correlated with NPP than temperature in the ASAC. In other words, compared with rising temperatures, the increase in precipitation is more beneficial to vegetation growth because soil moisture rises. It enhances photosynthesis and improves vegetation productivity (Griffin et al., 2004; Ciais et al., 2005). However, the situation is far more complicated when it comes to temperature increases, especially in arid areas. Temperature not only influences photosynthesis and respiration, it also strengthens evapotranspiration and reduces soil moisture (Miyashita et al., 2005; Brohan et al., 2006). Pure high temperature will give rise to drought and will limit the growth of grassland, leading to a downward trend in NPP (Zha et al., 2005).

When compared with the correlations between NPP and temperature variables, the results for autumn and winter are similar to those for annual data. However, spring and summer have unique characteristics. In spring, the correlation between NPP and spring temperature shows significant regional differences. Positive correlation areas are mostly found in the eastern ASAC, while the western ASAC generally demonstrated a negative correlation. This finding may be due to the fact that the eastern ASAC is largely covered by forest steppes, that the increase in spring temperature advances the beginning dates of the growing seasons of this vegetation and that the NPP shows an upward trend as a result (Guo et al., 2010; Wang et al., 2011). In the western ASAC, such vegetation as alpine meadow is the main species in that area. Previous studies have shown that the frozen soil in spring plays an active role in vegetation productivity in the alpine meadow. It serves as a water resource, and compensates for the lack of precipitation in the spring for plants, helping to promote the growing season. Frozen soil also maintains the soil fertility and increases the thermal capacity of the soil (Li et al., 2001; Gao Rong et al., 2004). When spring temperatures begin to rise, frozen soil melts earlier, a process that speeds up the decomposition of soil organic matter and reduces soil fertility. Eventually, the increase in spring temperatures may negatively impact vegetation productivity (Li et al., 2005). In summer, most areas in the ASAC show a negative correlation between NPP and temperature. Multiple studies have pointed out that the summer drought trend in the ASAC is worsening (Cheng et al., 2012; Ren et al., 2014; Zhang et al., 2014). In this water-limited region, when temperature increases by $0.5-2.0^{\circ} \mathrm{C}$, evapotranspiration will rise 0.2-2.0 mm/d (Mabutt, 1989; Greco et al., 1994). If rainfall can not adequately supplement evapotranspiration, the increased temperature is sure to suppress the growth of vegetation. Therefore, although the ASAC is growing warmer and wetter at the interannual scale, the drought will still cause a decrease in NPP over the summer.

The results of analysis of the correlation between NPP and precipitation variables show that at both the interannual scale and the seasonal scale, most areas in the ASAC are positively correlated. In spring, however, negative correlation areas are concentrated in the eastern ASAC in the Da Hinggan Ling Prefecture; this finding is similar to that of $\mathrm{Yu}$ et al. (2014). This phenomenon may be ascribed to the frost risk. Based on our analysis of the spring temperature and precipitation trend in this area, decreasing temperatures and increasing precipitation may easily cause spring frost, which can reduce plant growth at the beginning of the growing season (Carol, 2009; Eccel et al., 2009). In autumn and winter, negatively correlated areas are distributed in Xinjiang and Inner Mongolia, respectively. According to related research, cold waves are one of the main forms of natural disasters in this area (Wang and Ding, 2006; Mansur, 2012). Temperatures decrease extensively during this period, and with increasing precipitation, vegetation easily suffers from frostbite.

\section{Conclusions}

In this study, we analyzed CRU climatic data and MODIS data and successfully established correlations between NPP and climatic variables. The climate in the ASAC has grown warmer and wetter over the past decade. NPP in the ASAC has increased in recent years; the vegetation conditions in this area have improved significantly. Temperatures in winter and precipitation in summer are limiting factors for NPP in the whole re- 
gion. The temperature in spring and the precipitation in autumn are less important in the west, as opposed to the east, in which both are critically important. NPP in the ASAC is more sensitive to precipitation than to temperature.

Research on the influence of seasonal climate variables on NPP can help scientists understand the relation between vegetation growth and climate changes and is therefore a central focus for the global scientific community. Our findings indicate clear differences in the correlation between NPP and climate variables for annual data and seasonal data. Most research on vegetation has focused exclusively on annual climate data. The results of this study may serve as a step towards illuminating the responses of vegetation NPP to global change in the ASAC. These findings not only underline the importance of seasonal climate variables for vegetation growth, but also suggest that the effects of seasonal climate variables on vegetation growth should be included in future research in this field.

\section{References}

Brohan P, Kennedy J J, Harris I et al., 2006. Uncertainty estimates in regional and global observed temperature change: a new data set from 1850. Journal of Geophysical Research-Atmospheres, 111(D12). doi: 12110.11029/12005JD00 6548

Cao M K, Woodward F I, 1998. Dynamic responses of terrestrial ecosystem carbon cycling to global climate change. Nature, 393(6682): 249-252. doi: 10.1038/30460

Carol K A, 2009. Spring 2007 warmth and frost: phenology, damage and refoliation in a temperate deciduous forest. Functional Ecology, 23(6): 1031-1039. doi: 10.1111/j.1365-2435. 2009.01587.x

Chen F H, Chen J H, Holmes J et al., 2010. Moisture changes over the last millennium in arid central Asia: a review, synthesis and comparison with monsoon region. Quaternary Science Reviews, 29(7-8): 1055-1068. doi: 10.1016/j.quascirev.2010. 01.005

Chen Fujun, Shen Yanjun, Li Qian et al., 2011. Spatio-temporal variation analysis of ecological systems NPP in China in past 30 years. Scientia Geographica Sinica, 31(11): 1409-1411. (in Chinese)

Chen Yanmei, Gao Jixi, Feng Chaoyang et al., 2012. Temporal and spatial distribution of vegetation Net Primary Productivity (NPP) in the years from 1982 to 2010 in Hulunbeier. Journal of Ecology and Rural Environment, 28(6): 647-653. (in Chinese)

Cheng Man, Wang Ranghui, Xue Hongxi et al., 2012. Effects of drought on ecosystem net primary production in northwestern
China. Journal of Arid Land Resources and Environment, 26(6):1-7. (in Chinese)

Ciais P h, Reichstein M, Viovy N et al., 2005. Europe-wide reduction in primary productivity caused by the heat and drought in 2003. Nature, 437(7058): 529-533. doi: 10.1038/nature 03972

Dai A G, 2011. Drought under global warming: a review. Wiley Interdisciplinary Reviews-Climate Change, 2(1): 45-65. doi: 10.1002/wcc.81.

Del S G, Parton W, Stohlgren T et al., 2008. Global potential net primary production predicted from vegetation class, precipitation, and temperature. Ecological Society of America, 89(8): 2117-2126. doi: 10.1890/07-0850.1.

Department of Geography, Northwest Normal University, 1984. Chinese Atlas of Physical Geography. Beijing: China Cartographic Publishing House.

Eccel E, Rea R, Caffarra A et al., 2009. Risk of spring frost to apple production under future climate scenarios: the role of phenological acclimation. International Journal of Biometeorology, 53(3): 273-286. doi: 10.1007/s00484-009-0213-8

Friend A D, Lucht W, Rademacher T T et al., 2014. Carbon residence time dominates uncertainty in terrestrial vegetation responses to future climate and atmospheric $\mathrm{CO}_{2}$. PNAS, 111(9): 3280-3285. doi: 10.1073/pnas.1222477110

Gao Q Z, Li Y, Wan Y F et al., 2009. Dynamics of alpine grassland NPP and its response to climate change in Northern Tibet. Climate Change, 97(4): 515-528. doi: 10.1007/s10584-0099617-z

Gao Rong, Wei Zhigang, Dong Wenjie, 2004. Analysis of the cause of the differentia in interannual variation between snow cover and seasonal frozen soil in the Tibetan Plateau. Journal of Glaciology and Geocryoloy, 26(2): 153-159. (in Chinese)

Gao Zhiqiang, Liu Jiyuan, Cao Mingkui et al., 2004. Impacts of land use and climate change on regional net primary productivity. Acta Geographica Sinica, 59(4): 581-591. (in Chinese)

Guo Zhixing, Zhang Xiaoning, Wang Zongming et al., 2010. Responses of vegetation phenology in Northeast China to climate change. Chinese Journal of Ecology, 29(3): 578-585. (in Chinese)

Greco S, Moss R H, Viner D et al., 1994. Climate Scenarios and Socioeconomic Projections for IPCC WG II Assessment. Washington, DC: IPCC and UNEP.

Griffin J J, Ranney T G, Pharr D M, 2004. Heat and drought influence photosynthesis, water relations, and soluble carbohydrates of two ecotypes of redbud (Cercis canadensis). Journal of the American Society for Hortcultural Science, 129(4): 497-502.

Hicke J A, Asner G P, Randerson J T et al., 2002. Trends in north American net primary productivity derived from satellite observations, 1982-1999. Global Biogeochemical Cycles, 16 (2): 1-14. doi: 10.1029/2001GB001550

Huang M, Peng G B, Leslie L M et al., 2005. Seasonal and regional temperature changes in China over the 50 year period 1951-2000. Meteorology and Atmospheric Physics, 89(1-4): 105-115. doi: 10.1007/s00703-005-0124-0 
Houghton J T, Ding Y, Griggs D J et al., 2001. Climate Change 2001: The Scientific Basis. Cambridge University Press, Cambridge.

Houghton R A, 2002. Terrestrial carbon sinks-uncertain explanations. Biologist, 49(4):155-160.

Houghton R A, Hackler J L, Lawrence K T, 1999. The U.S. carbon budget: contributions from land-use change. Science, 7(5427): 574-578. doi: 10.1126/science.285.5427.574

IPCC (Intergovernmental Panel on Climate Change), 2007. Summary for Policymakers of the Synthesis Report of the IPCC Fourth Assessment Report. UK Cambridge: Cambridge University Press.

Jones P D, Moberg A, 2003. Hemispheric and large-scale surface air temperature variations: an extensive and an update to 2001 . Journal of Climate, 16(3): 206-223. doi: 10.1175/1520-0442 (2003)

Keeling C D, Chin J F S, Whorf T P, 1996. Increased activity of northern vegetation in inferred from atmospheric $\mathrm{CO}_{2}$ measurements. Nature, 382(6587): 146-149. doi: 10.1038/382146a0

Knapp A K, Smith M D, 2001. Variation among biomes in temporal dynamics of aboveground primary production. Science, 291(5503): 481-484. doi: 10.1126/science.291.5503.481

Li Fei, Zhao Jun, Zhao Chunyan et al., 2011. Simulating and analyzing dynamic change of potential vegetation in arid areas of Northwest China. Acta Prataculturae Sinica, 20(4): 42-50. (in Chinese)

Li Junyuan, Xu Weixin, Cheng Zhigang et al., 2012. Spatial-temporal changes of climate and vegetation cover in the semi-arid and arid regions of China during 1982-2006. Ecology and Environmental Sciences, 21(2): 268-272. (in Chinese)

Li Wanyuan, Qian Zhengan, 2005. Temporal and spatial feature analyses of winter and summer surface air temperature to in CMASA, Part (I): January. Plateau Meteorology, 24(6): 889-897. (in Chinese)

Li Yingnian, Bao Xinkui, Cao Guangmin, 2001. Comparison of the earth temperature between fiborthic histosols and Mat-Cryic cambisols in Tibet Plateau. Acta Pedologica Sinica, 38(2): 145-152. (in Chinese)

Li Yingnian, Guan Dingguo, Zhao Liang et al., 2005. Seasonal frozen soil and its effect on vegetation production in Haibei alpine meadow. Journal of Glaciology and Geoceyology, 27(3): 311-319. (in Chinese)

Li Z S, Liu G H, Fu B J et al., 2011. The potential influence of seasonal climate variables on the net primary production of forests in Eastern China. Environmental Management, 48(6): 1173-1181. doi: 10.1007/s00267-011-9710-8

Liu B H, Xu M, Henderson M et al., 2004. Taking China's temperature: daily range, warming trends, and regional variations, 1955-2000. Journal of Climate, 17(22): 4453-4462. doi: 10. $1175 / 3230.1$

Mabutt, J A, 1989. Impacts of carbon dioxide warming on climate and man in the semi-arid tropics. Climatic Change, 15(1-2): 191-221. doi: 10.1007/BF00138852

Mansur Sabit, 2012. Climatic characteristics of cold wave and its impact on agriculture in southern Xinjiang in recent 60 years.
Journal of Natural Resources, 27(12): 2145-2152. (in Chinese)

Melillo J M, McGuire A D, Kicklighter D W et al., 1993. Global climate change and terrestrial net primary production. Nature, 363(6426): 234-240. doi: 10.1038/363234a0

Mitchell T D, Jones P D, 2005. An improved method of constructing a database of monthly climate observations and associated high-resolution grids. International Journal of Climatology, 25(6): 693-712. doi: 10.1002/joc.1181

Miyashita K, Tanakamaru S, Maitani T et al., 2005. Recovery responses of photosynthesis, transpiration, and stomatal conductance in kidney bean following drought stress. Environmental and Experimental Botany, 53(2): 205-214. doi: 10. 1016/j.envexpbot.2004.03.015

Myneni R B, Dong J, Tucker C J et al., 2001. A large carbon sink in the woody biomass of northern forests. Proceedings of the National Academy of Sciences of the United States of America, 98(26): 14784-14789. doi: 10.1073/pnas.261555198

Narisma G T, Foley J A, Licker R et al., 2007. Abrupt changes in rainfall during the twentieth century. Geophysical Research Letters, 34(6): L06710. doi: 10.1029/ 2006GL028628

Nemani R R, Keeling C D, Hashimoto H et al., 2003. Climate-driven increases in global terrestrial net primary production from 1982 to 1999. Science, 300(5625): 1560-1563. doi: $10.1126 /$ science. 1082750

Nemani R R, White M, Thornton P et al., 2002. Recent trends in hydrologic cycle have enhanced terrestrial carbon sink in the US. Geophysical Research Letters, 29(10): 106-1-106-4. doi: 10.1029/2002GL014867

Peng Qin, Qi Yuchun, Dong Yunshe et al., 2012. Responses of carbon cycling key processes to precipitation changes in arid and semiarid grassland ecosystems: a review. Progress in $\mathrm{Ge}$ ography, 31(11): 1510-1518. (in Chinese)

Piao Shilong, Fang Jingyun, Guo Qinghua, 2001. Terrestrial net primary production and its spatiotemporal patterns in China during 1982-1999. Acta Scientiarum Naturalium Universitatis Pekinensis, 37(4): 563-569. (in Chinese)

Piao S L, Ciais P, Friedlingstein Pierre et al., 2008. Net carbon dioxide losses of northern ecosystems in response to autumn warming. Nature, 451(7174): 49-52. doi: 10.1038/nature06444

Piao S L, Fang J Y, Chen A P, 2003. Seasonal dynamics of terrestrial net primary production in response to climate changes in China. Acta Botanica Sinica, 45(3): 269-275.

Ren Chaoxia, Yang Dayuan, 2006. Variations trend of climate of Northwest area in China in the last 50 Years. Quaternary Sciences, 26 (2): 299-300. (in Chinese)

Ren Peigui, Zhang Bo, Zhang Tiaofeng et al., 2014. Trend Analysis of Meteorological Drought Change in Northwest China Based on Standardized Precipitation Evapotranspiration Index. Bulletin of Soil and Water Conservation, 34(1): 182187. (in Chinese)

Shi Yafeng, Shen Yongping, Li Dongliang et al., 2003. Discussion on the present climate change from warm-dry to warmwet in North-west China. Quaternary Sciences, 23(2): 152164. (in Chinese)

Shi Y F, Shen Y P, Kang E et al., 2007. Recent and future climate 
change in northwest china. Climatic Change, 80(3-4): 379-393. doi: 10.1007/s10584-006-9121-7

Tao Bo, Li Kerang, Shao Xuemei et al., 2003. Temporal and spatial pattern of net primary production of terrestrial ecosystems in China. Acta Geographica Sinica, 58(3): 372-380. (in Chinese)

Tian H, Melillo J M, Kicklighter D W et al., 1999. The sensitivity of terrestrial carbon storage to historical climate variability and atmospheric $\mathrm{CO}_{2}$ in the United States. Tellus, 51(2): 414-452. doi: 10.1034/j.1600-0889.1999.00021.x

Wang Genxu, Chen Guodong, Xu Zhongmin, 1999. The utilization of water resource and its influence on eco-environment in the northwest arid area of China. Journal of Natural Resources, 14(2): 109-116. (in Chinese)

Wang Lei, Ding Jingjing, Ji Yonghua et al., 2009. Spatiotemporal pattern of NPP in terrestrial ecosystem of China from 1981 to 2000. Journal of Jiangsu Forestry Science \& Technology, 36(6): 1-5. (in Chinese)

Wang X H, Piao S L, Ciais P et al., 2011. Spring temperature change and its implication in the change of vegetation growth in North America from 1982 to 2006. Proceedings of the $\mathrm{Na}$ tional Academy of Sciences of the United States of America, 108(4): 1240-1245. doi: 10.1073/pnas.1014425108

Wang Zunya, Ding Yihui, 2006. Climate change of the cold wave frequency of China in the last 53 years and the possible reasons. Chinese Journal of Atmospheric Sciences, 30(6): 1068-1076. (in Chinese)

Wen Xinyu, Wang Shaowu, Zhu Jinhong, 2006. An overview of China climate change over the 20th century using UK UEA/CRU high resolution grid data. China Journal of Atmospheric Sciences, 30(5): 894-903. (in Chinese)

Yao Junqiang, Yang Qing, Chen Yaning et al., 2013. Climate change in arid areas of Northwest China in past 50 years and its effects on the local ecological environment. Chinese Journal of Ecology, 32(5): 1283-1291. (in Chinese)

Yu Haiyan, Liu Shuhua, Zhao Na et al., 2011. Characteristics of air temperature and precipitation in different regions of China from 1951 to 2009. Journal of Meteorology and Environment, 27(4): 1-11. (in Chinese)

Yu X F, Wang Q K, Yan H M et al., 2014. Forest phenology dynamics and its responses to meteorological variations in Northeast China. Advances in Meteorology, Article ID 592106, 12. doi: 10.1155/2014/592106

Zha Y, Gao J, Zhang Y, 2005. Grassland productivity in an alpine environment in response to climate change. Area, 37(3): 332-340. doi: 10.1111/j.1475-4762.2005.00637.x

Zhai P M, Sun A J, Ren F M et al., 1999. Changes of climate extremes in China. Climatic Change, 42(1): 203-218. doi: 10.1023/A:1005428602279

Zhang B Q, Wu P T, Zhao X N et al., 2014. Spatiotemporal analysis of climate variability (1971-2010) in spring and summer on the Loess Plateau, China. Hydrological Processes, 28(4): 1689-1702. doi: 10.1002/hyp.9724

Zhang G L, Zhang Y J, Dong J W et al., 2013. Green-up dates in the Tibetan Plateau have continuously advanced from 1982 to 2011. PNAS, 110(11): 4309-4314. doi: 10.1073/pnas.1210423 110

Zhao M S, Heinseh F A, Nemani R R et al., 2005. Improvements of the MODIS terrestrial gross and net primary production global dataset. Remote Sensing of Environment, 95(2): 164176. doi: 10.1016/j.rse.2004.12.011

Zhao M S, Running S W, 2010. Drought-induced reduction in global terrestrial net primary production from 2000 through 2009. Science, 329(5994): 940-943. doi: 10.1126/science. 1192666

Zheng Yuanrun, Zhou Guangsheng, Zhang Xinshi et al., 1997. Sensitivity of terrestrial ecosystem to global change in China. Acta Botanica Sinica, 39(9): 837-840. (in Chinese)

Zhou G S, Wang Y H, Jiang Y L et al., 2002. Estimating biomass and net primary production from forest inventory data: a case study of China's Larixforests. Forest Ecology and Management, 169(1-2): 149-157. doi: 10.1016/S0378-1127(02)00305-5

Zhou Guangsheng, Zhang Xinshi, 1996. Study on NPP of natural vegetation in China under global climate change. Acta Phytoecologica Sinica, 20(1): 11-19. (in Chinese)

Zhou L M, Tucker C J, Kaufmann R K et al., 2001. Variations in northern vegetation activity inferred from satellite data of vegetation index during 1981 to 1999. Journal of Geophysical Research Atmospheres, 106(D17): 20069-20083. doi: 10.1029/ 2000JD000115 